\title{
Familial risk assessment for early-onset coronary heart disease
}

\author{
Maren T. Scheuner, MD, MPH ${ }^{1,2}$, William C. Whitworth, MPH ${ }^{2}$, Henraya McGruder, PhD, MS $S^{3}$, \\ Paula W. Yoon, ScD, $M P H^{2}$, and Muin J. Khoury, $M D, P h D^{2}$
}

\begin{abstract}
Purpose: We examined the performance of a familial risk assessment method that stratifies risk for early-onset coronary heart disease by considering the number of relatives with coronary disease, degree of relationship, lineage, and age at diagnosis. Methods: By using data from the HealthStyles 2003 survey, we assessed the associations between familial risk and early-onset coronary heart disease, diabetes, hypercholesterolemia, hypertension, and obesity. By using area under the curve statistics, we evaluated the discriminatory ability of various risk assessment models. Results: Of 4035 respondents, $60 \%$ were female and $72 \%$ were white, with a mean age of 48.8 years. After adjustment for demographics, strong and moderate risk were significantly associated with approximately a five- and twofold risk of early-onset coronary disease, respectively. After adjustment for demographics and personal history of cardiovascular disease, strong familial risk was also significantly associated with diabetes, hypercholesterolemia, hypertension, and obesity. A risk assessment model that included familial risk, demographics, and personal history of diabetes, hypercholesterolemia, hypertension, and obesity was most optimal with an area under the curve statistic of 87.2\%. Conclusions: Familial risk assessment can stratify risk for early-onset coronary heart disease. Several conditions associated with increased familial risk can be prevented. These results have important implications for risk assessment and risk-reducing interventions. Genet Med 2006:8(8):525-531.
\end{abstract}

Family history is one of the most important risk factors for early-onset coronary heart disease (CHD). Many studies have found an increase in CHD of approximately two- to threefold given a first-degree relative with $\mathrm{CHD},{ }^{1-4}$ and the strength of this association increases as the number of affected first-degree relatives increases ${ }^{5-10}$ and with younger ages of CHD onset. ${ }^{1,5-7,9,11-13}$ Studies that have investigated family histories of late-onset CHD have also found significant positive associations with $\mathrm{CHD}$, although the relative risks are comparatively smaller. ${ }^{5,6,9,11-13}$ Recent studies have demonstrated an increased CHD risk associated with $\mathrm{CHD}$ in second-degree relatives, ${ }^{14,15}$ and in maternal relatives, ${ }^{13}$ although other studies have not found an association between CHD and lineage. ${ }^{4,7,10,16}$

Despite the importance of family history as a CHD risk factor, it is underused in CHD prevention efforts. Many standard risk assessment methods and guidelines underrate the significance of family history. ${ }^{17-20}$ If considered at all, assessment is

\footnotetext{
From the ${ }^{I}$ RAND Corporation, Santa Monica, California; ${ }^{2}$ Office of Genomics and Disease Prevention, Coordinating Center for Health Promotion, Centers for Disease Control and Prevention, Atlanta, Georgia; and ${ }^{3}$ Division of Heart Disease and Stroke Prevention, $\mathrm{Na}$ tional Center for Chronic Disease Prevention and Health Promotion, Coordinating Center for Health Promotion, Centers for Disease Control and Prevention, Atlanta, Georgia.

Maren T. Scheuner, MD, MPH, RAND Corporation, 1776 Main Street, P.O. Box 2138, Santa Monica, CA 90407-2138.

Submitted for publication March 16, 2006.
}

Accepted for publication June 1, 2006.

DOI: 10.1097/01.gim.0000232480.00293.00 generally limited to early-onset CHD in first-degree relatives only. Many clinicians are also reluctant to assess family history as a disease risk factor because of concerns about the amount of time required to collect the information and their ability to interpret the information accurately. ${ }^{21-24}$

To address these barriers, several national organizations and federal agencies have endorsed the development and use of family history tools, particularly for common chronic diseases, such as CHD, diabetes, and cancer. ${ }^{25-29}$ These tools are designed to (1) aid in identifying people with increased disease risk attributable in part to genetic factors; (2) improve early detection and prevention efforts for people with increased familial risk; and (3) facilitate the referral of individuals for genetic evaluation, including genetic counseling and testing. These tools can range from simple guidelines on the collection of family history to complex algorithms that interpret family history data and provide prevention messages tailored to the level of familial risk.

A method of familial risk stratification has been developed that assesses an individual's familial risk for CHD as weak, moderate, or strong based on whether and at what age (i.e., early, late, or unknown) first- and second-degree relatives were diagnosed with CHD. The goal of this study was to determine the prevalence of these familial risk categories for CHD in a cross-sectional study of the U.S. population, and to assess the performance of the stratification method by measuring associations with demographic factors, prevalent $\mathrm{CHD}$, and related medical conditions. 


\section{METHODS}

\section{Subjects}

Data from the HealthStyles 2003 survey were used for this cross-sectional study. HealthStyles, an annual mail survey of health-related attitudes and behaviors among the U.S. adult population, ${ }^{30}$ is a subset of a two-part consumer survey designed and conducted by Synovate, Inc. (Arlington Heights, IL), a marketing firm that annually recruits approximately 600,000 potential respondents. The survey is used for health communications planning by organizations (including the U.S. Centers for Disease Control and Prevention) that influence the design and administration of the questionnaire. From a stratified random sample of 5845 adults, 4035 (69\%) agreed to participate in HealthStyles 2003. The survey sampling was generated on the basis of age, sex, marital status, race/ethnicity, income, geographic region, household size, and population density. One adult per household was asked to respond. Lowincome and minority households were oversampled to improve their representation. ${ }^{30}$ The Centers for Disease Control and Prevention Institutional Review Board approved this study.

Respondents provided information about their age, sex, ethnicity/race, education, income, marital status, and medical history, including both personal and family history of CHD. Personal history of CHD was considered present if a respondent reported that a doctor had diagnosed CHD, such as myocardial infarction, coronary bypass graft surgery, or angioplasty. Angina was not included in the definition. Personal history of stroke was considered present if a respondent reported that a doctor had diagnosed stroke or transient ischemic attack. For both CHD and stroke, respondents indicated whether their diagnosis came at or before age 60 years (early onset) or after age 60 years (late onset). Respondents were considered to have diabetes or obesity if they reported having either condition currently or within the past year. Hypercholesterolemia was coded as present if respondents reported ever being told by a health professional that they had high blood cholesterol or were told to take medication for high cholesterol. Hypertension was considered present if respondents reported ever being told on two or more office visits that they had high blood pressure or were ever prescribed medication to lower their blood pressure. Hypertension or diabetes diagnosed during pregnancy was excluded.

\section{Family history assessment}

Family history was obtained from respondents by asking them whether CHD had been diagnosed at or before age 60 years (early onset) or after age 60 years (late onset) in firstdegree relatives (mother, father, and siblings) and second-degree relatives (aunts, uncles, and grandparents). Response options included "yes," "no," and "don't know." Respondents also reported whether they had zero, one, or two or more siblings or second-degree relatives diagnosed with CHD.

The method of familial risk assessment under evaluation in this study used a hierarchal array of specific characteristics that took into account whether CHD was diagnosed at an early, late, or unknown age of onset in a respondent's first- and second-degree relatives, and was based on empirical data from the literature. ${ }^{31,32}$ A weak risk was assigned if there was (1) no family history of CHD or (2) CHD in only one second-degree relative from one or both sides of the family. Moderate risk was assigned if there was (1) only one first-degree relative with late-onset $\mathrm{CHD},(2)$ only one first-degree relative with lateonset $\mathrm{CHD}$ and one second-degree related with late-onset CHD from the same lineage, (3) only a mother and a father with late-onset $\mathrm{CHD}$, (4) only one second-degree relative with early-onset $\mathrm{CHD}$ and one second-degree relative with lateonset CHD from the same lineage, or (5) only two seconddegree relatives with late-onset CHD from the same lineage. Strong familial risk was assigned for all other family histories of $\mathrm{CHD}$, including having at least one first-degree relative with early-onset CHD, and combinations of multiple affected family members. "Don't know" responses were considered as "no" responses.

\section{Statistical analyses}

We used descriptive statistics to characterize respondents, chi-square tests to assess differences in proportions, and the Student $t$ test to assess differences in means. Odds ratios (ORs) were calculated to assess associations between self-reported early-onset CHD compared with late-onset CHD $(n=79)$ and no $\mathrm{CHD}$, and moderate or strong familial CHD risk compared with the referent of weak familial risk using multivariate logistic regression with (1) adjustment for demographic factors only and (2) adjustment for demographics plus personal history of stroke, obesity, hypertension, hypercholesterolemia, and diabetes. Similar calculations were conducted to assess the associations between moderate or strong familial CHD risk and diabetes, hypercholesterolemia, hypertension, and obesity after (1) adjusting for demographic factors only and (2) adjusting for demographics plus personal history of CHD and stroke at any age of onset. The Breslow Day test for OR heterogeneity was performed to assess interactions between the different levels of familial risk and diabetes, hypercholesterolemia, hypertension, and obesity. No significant interactions were found $(P<.05)$; therefore, none were included in the models. The ability to identify people with reported early-onset CHD using risk assessment models that included familial risk stratification, demographic factors, and the related conditions of diabetes, hypercholesterolemia, hypertension, and obesity (both alone and in combination) was evaluated using area under the curve (AUC) statistics, which were calculated using multivariate logistic regression. AUC greater than 75\% suggested good discriminatory ability. All statistical analyses were performed using SAS v8.2 (SAS Institute, Cary, NC).

\section{RESULTS}

The characteristics of the 4035 respondents by category of familial risk of CHD are presented in Table 1. Of the total population sample, $60 \%$ were female and $72 \%$ were white with 
Familial risk assessment for $\mathrm{CHD}$

Table 1

Characteristics of respondents overall and by familial coronary heart disease risk categories (HealthStyles 2003 Survey of Health-related Attitudes and Behaviors Among the U.S. Adult Population $)^{a}$

\begin{tabular}{|c|c|c|c|c|}
\hline \multirow[b]{2}{*}{ Characteristic } & \multicolumn{4}{|c|}{ Familial risk } \\
\hline & $\begin{array}{c}\text { Total } \\
(\mathrm{n}=4035) \\
\mathrm{N}(\%)\end{array}$ & $\begin{array}{c}\text { Strong } \\
(\mathrm{n}=1273) \\
\mathrm{N}(\%)\end{array}$ & $\begin{array}{c}\text { Moderate } \\
(\mathrm{n}=471) \\
\mathrm{N}(\%)\end{array}$ & $\begin{array}{c}\text { Weak } \\
(\mathrm{n}=2291) \\
\mathrm{N}(\%)\end{array}$ \\
\hline \multicolumn{5}{|l|}{ Sex } \\
\hline Female & $2427(60.1)$ & $784(61.6)$ & $274(58.2)$ & $1369(59.8)$ \\
\hline Male & $1608(39.9)$ & $489(38.4)$ & $197(41.8)$ & $922(40.2)$ \\
\hline \multicolumn{5}{|l|}{ Age group $^{b}$} \\
\hline $18-34$ y & $700(17.3)$ & $122(9.6)^{d}$ & $39(8.3)^{d}$ & $539(23.5)$ \\
\hline $35-44$ y & $1104(27.4)$ & $293(23.0)$ & $130(27.6)$ & $681(29.7)$ \\
\hline $45-54$ y & $1010(25.0)$ & $353(27.7)$ & $143(30.4)$ & $514(22.4)$ \\
\hline $55-64$ y & $558(13.8)$ & $234(18.4)^{d}$ & $69(14.6)$ & $255(11.1)$ \\
\hline $65+y$ & $663(16.4)$ & $271(21.3)^{d}$ & $90(19.1)$ & $302(13.2)$ \\
\hline \multicolumn{5}{|l|}{ Race/ethnicity } \\
\hline White & $2901(71.9)$ & $979(76.9)^{d}$ & $368(78.1)^{d}$ & $1554(67.8)^{d}$ \\
\hline African American & $493(12.2)$ & $124(9.7)$ & $38(8.1)$ & $331(14.4)$ \\
\hline Hispanic & $449(11.1)$ & $115(9.0)$ & $45(9.6)$ & $289(12.6)$ \\
\hline Asian & $139(3.4)$ & $35(2.7)$ & $13(2.8)$ & $91(4.0)$ \\
\hline Other & $53(1.3)$ & $20(1.6)$ & $7(1.5)$ & $26(1.1)$ \\
\hline \multicolumn{5}{|l|}{ Education $^{c}$} \\
\hline$\leq$ High school graduate & $1317(32.6)$ & 457 (35.9) & $120(25.5)$ & $740(32.3)$ \\
\hline Some college & $1318(32.7)$ & $398(31.3)$ & $165(35.0)$ & $755(33.0)$ \\
\hline$\geq$ College graduate & $1128(28.0)$ & $346(27.2)$ & $156(33.1)$ & $626(27.3)$ \\
\hline \multicolumn{5}{|l|}{ Income } \\
\hline$\geq \$ 35,000$ & $2290(56.8)$ & $703(55.2)$ & $303(64.3)$ & $1284(56.0)$ \\
\hline$<\$ 35,000$ & $1745(43.2)$ & $570(44.8)$ & $168(35.7)$ & $1007(44.0)$ \\
\hline \multicolumn{5}{|l|}{ Marital status } \\
\hline Ever married or cohabitating & $3508(86.9)$ & $1142(89.7)$ & $427(90.7)$ & $1939(84.6)$ \\
\hline Never married & $527(13.1)$ & $131(10.3)$ & $44(9.3)$ & $352(15.4)$ \\
\hline Early-onset CHD & $178(4.4)$ & $122(9.6)^{d}$ & $16(3.4)$ & $40(1.7)^{d}$ \\
\hline Late-onset CHD & $79(2.0)$ & $43(3.4)$ & $13(2.8)$ & $23(1.0)$ \\
\hline Early-onset stroke & $121(3.0)$ & $65(5.1)^{d}$ & $18(3.8)$ & $38(1.7)$ \\
\hline Late-onset stroke & $50(1.2)$ & $28(2.2)$ & $2(0.4)$ & $20(0.9)$ \\
\hline Diabetes & $495(12.3)$ & $213(16.7)^{d}$ & $50(10.6)$ & $232(10.1)$ \\
\hline Obesity & $700(17.3)$ & $274(21.5)^{d}$ & $82(17.4)$ & $344(15.0)$ \\
\hline Hypertension & $1336(33.1)$ & $539(42.3)^{d}$ & $158(33.5)$ & $639(27.9)^{d}$ \\
\hline Hypercholesterolemia & $1376(34.1)$ & $548(43.0)^{d}$ & $193(41.0)$ & $635(27.7)^{d}$ \\
\hline
\end{tabular}

CHD, coronary heart disease.

${ }^{a}$ Early-onset CHD, disease at or before age 60 years; late-onset CHD, disease after age 60 years.

${ }^{b}$ Mean age (standard deviation) for total population, 48.4 years (14.4); for strong familial risk, 52.2 years $(13.7), P<.0001$; moderate familial risk, 51.0 years (13.6),

$P<.0001$; and weak familial risk, 45.7 (14.5), $P<.0001$. $P$ values compared mean values with the mean age (48.4 years) among all respondents.

${ }^{c}$ Educational status missing for 272 respondents.

${ }^{d}$ Significant $(<.05) P$ values corrected for 81 comparisons of frequencies of characteristics with frequencies among all respondents. 
a mean age of 48.4 years (standard deviation 14.4). The mean ages of respondents with strong and weak familial risk of CHD were significantly older and younger, respectively, than the mean age of the total population $(P<.0001)$. Significantly more white respondents had strong and moderate familial risk, and fewer white respondents had weak familial risk than respondents of other ethnic/racial groups. No significant differences were found between the proportion of other ethnic/racial groups among the different familial risk groups and the total population. In addition, no significant differences were found between the frequencies of educational level, income, or marital status among the respondents in different familial risk categories and the total population. However, compared with the total population frequencies, significantly more respondents in the strong familial risk group reported personal history of early-onset CHD, earlyonset stroke, diabetes, obesity, hypertension, and hypercholesterolemia, and significantly more respondents in the weak familial risk group reported lower frequencies of early-onset $\mathrm{CHD}$, hypertension, and hypercholesterolemia. No significant differences in the frequency of these conditions were found between the moderate familial risk group and the total sample.

The results showed that $31.5 \%$ of respondents had strong familial risk of $\mathrm{CHD}, 11.7 \%$ had moderate familial risk of CHD, and 56.8\% had weak familial risk of CHD. Approximately half of the respondents reported having one or more first- or second-degree relatives with CHD. Respondents reported more "don't know" responses for second-degree relatives (maternal aunts, uncles, and grandparents, $31.7 \%$; paternal aunts, uncles, and grandparents, 38.4\%) compared with first-degree relatives (mother, 7.6\%; father, $11.4 \%$; siblings, $6.1 \%)$. Age, personal history of CHD, marital status, education, and income significantly influenced differences in proportions of "don't know" responses $(P<.05)$. Sex and ethnicity did not. The proportion of "don't know" responses was significantly different for mother versus father, and maternal aunts, uncles, and grandparents versus paternal aunts, uncles, and grandparents $\left(P<10^{-6}\right)$. However, these differences were not significant after adjustment for demographic variables and personal history of CHD.
Prevalence ORs for moderate and strong familial risk associated with early-onset CHD compared with weak familial risk are shown in Table 2. After adjustment for demographic factors, strong and moderate levels of familial risk were associated with a 4.9-fold (95\% confidence interval [CI], 3.3-7.2) and 2.0-fold (95\% CI, 1.1-3.6) increase, respectively, in risk of early-onset $\mathrm{CHD}$. Modest decreases were noted in the strength of these associations after additional adjustment for personal history of stroke at any age of onset and/or personal history of the related conditions of diabetes, hypercholesterolemia, hypertension, and obesity. Even with this additional adjustment, however, the association between early-onset $\mathrm{CHD}$ and strong familial risk remained significant.

Strong familial risk was significantly associated with diabetes $(\mathrm{OR}=1.5 ; 95 \% \mathrm{CI}, 1.3-1.8)$, hypertension $(\mathrm{OR}=1.5 ; 95 \%$ CI, 1.3-1.8), hypercholesterolemia (OR $=1.4$; 95\% CI, 1.6 1.9 ), and obesity ( $\mathrm{OR}=1.5 ; 95 \% \mathrm{CI}, 1.3-1.8)$. After adjustment for demographic factors, moderate familial risk was significantly associated with hypercholesterolemia $(\mathrm{OR}=1.5$; 95\% CI, 1.2-1.9) but not with the other conditions (Table 3). The strength of these associations was unchanged or only slightly reduced after adjusting for demographics plus personal history of CHD or stroke at any age of onset.

Table 4 shows the association of familial risk and the number of other conditions (i.e., diabetes, hypercholesterolemia, hypertension, and obesity) with early-onset CHD. Weak familial risk plus no other condition was the referent group. Earlyonset CHD increased exponentially as the number of conditions and familial risk increased. Strong familial risk plus three or more conditions was associated with a 62.2-fold increase (95\% CI, 18.5-209.1) in early-onset CHD compared with the referent group. Having weak familial risk plus three or more conditions $(\mathrm{OR}=16.5 ; 95 \% \mathrm{CI}, 4.4-61.2)$ was comparable to strong familial risk plus one condition $(\mathrm{OR}=17.9 ; 95 \% \mathrm{CI}$, 5.3-61.0).

In Table 5, the results of the AUC analyses are shown for seven different risk assessment models for early-onset CHD that consider alone or in combination: familial risk stratification; demographic factors; and personal history of diabetes,

Table 2

Associations between familial coronary heart disease risk categories and early-onset coronary heart disease

Early-onset

CHD $(\mathrm{n}=178)$

\begin{tabular}{llccc}
\cline { 2 - 5 } Familial risk level & $\begin{array}{c}\text { Adjusted for } \\
\text { demographics only } \\
\text { or }(95 \% \mathrm{CI})^{a}\end{array}$ & $\begin{array}{c}\text { Adjusted for } \\
\text { demographics and stroke } \\
\text { or }(95 \% \mathrm{CI})^{b}\end{array}$ & $\begin{array}{c}\text { Adjusted for } \\
\text { demographics and related conditions } \\
\text { or (95\% CI) }\end{array}$ & $\begin{array}{c}\text { Adjusted for demographics, } \\
\text { stroke, and related conditions } \\
\text { or }(95 \% \mathrm{CI})^{d}\end{array}$ \\
\hline Strong $(\mathrm{n}=1273)$ & $4.9(3.3-7.2)$ & $4.6(3.1-6.8)$ & $4.3(2.9-6.5)$ & $4.0(2.7-6.0)$ \\
Moderate $(\mathrm{n}=471)$ & $2.0(1.1-3.6)$ & $1.9(1.0-3.5)$ & $1.8(1.0-3.3)$ & $1.7(0.9-3.2)$ \\
Weak $(\mathrm{n}=2291)$ & 1.0 & 1.0 & 1.0 & 1.0 \\
\hline
\end{tabular}

CHD, coronary heart disease; early-onset CHD, disease at or before age 60 years; late-onset CHD, disease after age 60 years; OR, odds ratio; CI, confidence interval.

${ }^{a}$ Adjusted for age, sex, ethnicity, marital status, education, and income.

${ }^{b}$ Adjusted for age, sex, ethnicity, marital status, education, income, and personal history of stroke at any age of onset.

${ }^{c}$ Adjusted for age, sex, ethnicity, marital status, education, income, and personal history of obesity, hypertension, hypercholesterolemia, and diabetes.

${ }^{d}$ Adjusted for age, sex, ethnicity, marital status, education, income, and personal history of stroke, obesity, hypertension, hypercholesterolemia, and diabetes. 
Table 3

Associations between familial coronary heart disease risk categories and the related conditions of obesity, hypertension, hypercholesterolemia, and diabetes

\begin{tabular}{|c|c|c|c|c|}
\hline Familial risk level & $\begin{array}{c}\text { Obesity } \\
(n=700) \\
\text { or }(95 \% \mathrm{CI})\end{array}$ & $\begin{array}{l}\text { Hypertension } \\
(\mathrm{n}=1336) \\
\text { or }(95 \% \mathrm{CI})\end{array}$ & $\begin{array}{l}\text { Hypercholesterolemia } \\
(\mathrm{n}=1376) \\
\text { or }(95 \% \mathrm{CI})\end{array}$ & $\begin{array}{c}\text { Diabetes } \\
(\mathrm{n}=495) \\
\text { or }(95 \% \mathrm{CI})\end{array}$ \\
\hline \multirow[t]{2}{*}{ Strong $(\mathrm{n}=1273)$} & $1.5(1.3-1.8)^{a}$ & $1.5(1.3-1.8)^{a}$ & $1.4(1.6-1.9)^{a}$ & $1.6(1.3-2.0)^{a}$ \\
\hline & $1.4(1.2-1.7)^{b}$ & $1.4(1.2-1.6)^{b}$ & $1.4(1.2-1.7)^{b}$ & $1.4(1.1-1.7)^{b}$ \\
\hline \multirow[t]{2}{*}{ Moderate $(\mathrm{n}=471)$} & $1.2(0.9-1.6)^{a}$ & $1.2(0.9-1.5)^{a}$ & $1.5(1.2-1.9)^{a}$ & $1.0(0.7-1.4)^{a}$ \\
\hline & $1.2(0.9-1.6)^{b}$ & $1.1(0.9-1.4)^{b}$ & $1.5(1.2-1.9)^{b}$ & $1.0(0.6-1.3)^{b}$ \\
\hline Weak $(\mathrm{n}=2291)$ & 1.0 & 1.0 & 1.0 & 1.0 \\
\hline
\end{tabular}

CHD, coronary heart disease; OR, odds ratio; CI, confidence interval.

${ }^{a}$ Adjusted for age, sex, ethnicity, marital status, education, and income.

${ }^{b}$ Adjusted for age, sex, ethnicity, marital status, education, income, and personal history of CHD at any age of onset and stroke at any age of onset.

Table 4

Early-onset coronary heart disease associated with weak, moderate, and strong familial coronary heart disease risk

and increasing number of related conditions including obesity, hypertension, hypercholesterolemia, and diabetes

\begin{tabular}{lccc}
\hline & \multicolumn{3}{c}{ Early-onset CHD $(\mathrm{n}=178)$} \\
\cline { 2 - 4 } $\begin{array}{c}\text { Number of } \\
\text { related } \\
\text { conditions }\end{array}$ & $\begin{array}{c}\text { Weak } \\
\text { familial risk } \\
\text { or }(95 \% \mathrm{CI})^{a}\end{array}$ & $\begin{array}{c}\text { Moderate } \\
\text { familial risk } \\
(\mathrm{n}=471) \\
\text { or }(95 \% \mathrm{CI})^{a}\end{array}$ & $\begin{array}{c}\text { Strong } \\
\text { familial risk } \\
(\mathrm{n}=1273) \\
\text { or }(95 \% \mathrm{CI})^{a}\end{array}$ \\
\hline $0(\mathrm{n}=1716)$ & $1.0($ referent $)$ & $3.6(0.6-21.9)$ & $4.3(1.1-17.6)$ \\
$1(\mathrm{n}=1203)$ & $3.7(1.0-13.9)$ & $2.1(0.21-20.0)$ & $17.9(5.3-61.0)$ \\
$2(\mathrm{n}=740)$ & $12.6(3.6-44.4)$ & $27.8(7.2-106.8)$ & $48.6(14.8-160.0)$ \\
$\geq 3(\mathrm{n}=376)$ & $16.5(4.4-61.2)$ & $24.9(5.2-119.7)$ & $62.2(18.5-209.1)$
\end{tabular}

CHD, coronary heart disease; early-onset CHD, disease at or before age 60 years; OR, odds ratio; CI, confidence interval. Related conditions indicate obesity, hypertension, hypercholesterolemia, and diabetes.

${ }^{a}$ Adjusted for age, sex, ethnicity, marital status, education, and income.

hypercholesterolemia, hypertension, and obesity. Familial risk stratification alone had the smallest AUC value; however, it still had relatively good discriminatory ability (AUC 70.9\%). The discriminatory ability of the familial risk stratification model improved considerably with the addition of demographic factors or personal history of diabetes, hypercholesterolemia, hypertension, and obesity, with AUC values of $82.3 \%$ and $84.6 \%$, respectively. The optimum model for identifying people with early-onset CHD included assessments of all three criteria (i.e., familial risk; demographics; and personal history of diabetes, hypercholesterolemia, hypertension, and obesity), with an AUC of $87.2 \%$.

\section{DISCUSSION}

We found that a method of familial risk assessment that included information about family history of early- and lateonset CHD in first- and second-degree relatives could stratify risk for early-onset $\mathrm{CHD}$ into three categories, with an increase of approximately fivefold in early-onset CHD given a strong
Table 5

Ability of different coronary heart disease risk assessment models to identify people with early-onset coronary heart disease

\begin{tabular}{lc}
\hline Risk assessment model & AUC (\%) \\
\hline 1. Familial risk + demographics + related conditions & 87.2 \\
2. Familial risk + related conditions & 84.6 \\
3. Demographics + related conditions & 84.6 \\
4. Familial risk + demographics & 82.3 \\
5. Related conditions only & 80.1 \\
6. Demographics only & 76.7 \\
7. Familial risk only & 70.9 \\
\hline
\end{tabular}

$\mathrm{CHD}$, coronary heart disease; early-onset CHD, disease at or before age 60 years; AUC, area under the curve.

Demographics include age, sex, ethnicity, marital status, education, and income. Related conditions include diabetes, hypercholesterolemia, hypertension, and obesity. AUC statistics were calculated for each risk assessment model using multivariate logistic regression with personal history of earlyonset CHD as the outcome of interest. AUC values greater than $70 \%$ suggest good discriminatory ability. Model 1 includes familial risk assessment for CHD, demographic factors, and related conditions. Model 2 includes familial risk assessment and related conditions. Model 3 includes demographics and related conditions. Model 4 includes familial risk assessment and demographics. Model 5 includes only related conditions. Model 6 includes only demographic factors. Model 7 includes only familial risk assessment.

familial risk and a twofold increase in early-onset CHD given a moderate familial risk compared with a weak familial risk (Table 2). We also found that diabetes, hypercholesterolemia, hypertension, and obesity were associated with a 1.4- to 1.6-fold increase given strong familial risk, and that hypercholesterolemia was associated with a 1.5 -fold increase given moderate familial risk, suggesting aggregation of these conditions in the highest risk families, that is, families with early-onset CHD or multiple affected relatives (Table 3 ). Furthermore, as demonstrated in Table 4, the risk of early-onset CHD increased substantially when respondents had an increasing number of CHD risk factors (diabetes, hypercholesterolemia, hypertension, or obesity) in combination with moderate or strong familial risk, and the absence of these conditions diminished the association between family history and CHD. These results have important implications for $\mathrm{CHD}$ prevention and suggest 
that people with even the strongest family histories of CHD might benefit from interventions for these conditions, which were prevalent among respondents with increased familial risk. This finding is supported by the work of Tavani and colleagues, ${ }^{33}$ who showed that people with increased familial risk for CHD may derive the greatest benefit from preventive strategies intervening on lifestyle risk factors.

As reflected in the AUC analyses presented in Table 5, we found that familial risk stratification could distinguish between those with reported early-onset CHD and those without CHD (AUC $=70.9 \%$ ), and the ability to do so improved when we took into consideration demographic factors (AUC = $82.3 \%$ ), personal history of diabetes, hypercholesterolemia, hypertension and obesity (AUC $=84.6 \%$ ), or demographic factors and personal history of these risk factors (AUC = $87.2 \%$ ). These results suggest that the addition of familial risk assessment can add to the discriminatory ability of most CHD risk assessment methods in use today that do not include family history or that limit family history appraisal to the presence or absence of early-onset CHD in first-degree relatives. ${ }^{17-20}$ This finding is supported by a recent study demonstrating that $32 \%$ of 102 asymptomatic women (mean age 51.7 years) with family histories of premature CHD who had low global risk estimates (according to the Framingham risk assessment method) showed evidence of significant subclinical coronary atherosclerosis, which was defined as age- and sex-adjusted coronary artery calcium scores greater than the 75th percentile. ${ }^{34}$ Improving $\mathrm{CHD}$ risk assessment by including familial risk stratification is also appealing, because the collection of family medical history is inexpensive, and most people are aware of their family history and believe it is salient to their personal health. ${ }^{35}$ Furthermore, although family history is not modifiable, it can contribute to risk assessment, and the intensity of risk factor management can be modified according to the severity of the overall risk.

The major strengths of this study were the large number of respondents to the HealthStyles 2003 survey, with equal representation of the sexes across a range of adult age groups, and the fact that the survey data correlated well with surveillance data from the Behavior Risk Factor Surveillance System..$^{30}$ However, because of the small number of respondents with late-onset CHD ( $\mathrm{n}=79$ ), we were unable to assess the associations between familial risk and that outcome. In addition, although the survey was population based, it was subject to selection bias, because participation was voluntary; thus, the survey respondents were not randomly drawn from the U.S. population. Furthermore, the cross-sectional design prohibited us from establishing any temporal associations concerning family history as a CHD risk factor, and because the data were obtained from prevalent cases, the results may have been confounded by survival.

Another potential limitation was the lack of validation of self-reports. A previous study showed that self-reports of personal history of CHD and risk factors are reliable, ${ }^{36}$ and several studies have investigated the validity of family history reports. For family history of CHD in first-degree relatives, sensitivity ranged from $67 \%$ to $89 \%$, and specificity ranged from $59 \%$ to
97\%, with most values greater than $90 \% .{ }^{6,37-41}$ A personal history of CHD or having a CHD risk factor such as hypertension, diabetes, or hypercholesterolemia generally does not affect the accuracy of the family history report, nor does gender. ${ }^{38,39,41}$ However, older respondents are more likely than younger respondents to give inaccurate reports of family history. ${ }^{38,41}$ Limited information is available regarding the influence of ethnicity/race on the accuracy of family history reports. However, in the National Heart, Lung, and Blood Institute Family Heart Study, no significant differences were found in family history accuracy between whites and African Americans reporting on $\mathrm{CHD}$, diabetes, and hypertension. ${ }^{38}$ Given these estimates of validity, a family history of $\mathrm{CHD}$ generally can be considered as accurate, with little overreporting of disease in close family members.

Awareness of family history of CHD was less for seconddegree relatives compared with first-degree relatives. That is, there were fewer "don't know" responses for first-degree relatives. Because "don't know" responses were considered as "no" responses in the risk algorithms, this could lead to misclassification of some individuals as having a lower familial risk, thereby diminishing the strength of the associations we have described. Furthermore, because CHD in second-degree relatives was an important criterion in defining moderate familial risk, the lack of awareness of CHD status, particularly for second-degree relatives, may explain the lower prevalence of moderate familial risk relative to high familial risk.

We were also limited in our ability to assess all of the risk factors that might influence the association between increased familial risk of CHD and early-onset CHD, including lifestyle factors such as diet, smoking, or physical inactivity, because these data were not collected in the HealthStyles 2003 survey. Family members often share these risk factors, which could contribute to the increased familial risk that we observed in this study. However, we could not discern the contribution of these factors in our analyses, which also limited our ability to infer the possible benefit resulting from preventive interventions targeted to these risk factors.

\section{SUMMARY AND IMPLICATIONS}

Risk stratification using family history of CHD may improve standard global risk assessment methods for CHD. Familial risk for this disease is prevalent, and thus the evaluation of family history, in conjunction with demographics and other risk factors, should be considered as an initial step in risk assessment for CHD. Diabetes, hypercholesterolemia, hypertension, and obesity aggregate in high-risk families, and the risk of $\mathrm{CHD}$ associated with moderate and strong familial risk increases when these conditions are present and diminishes when they are absent. This finding suggests the potential benefit from preventive interventions on these risk factors for people with increased familial CHD risk.

\section{ACKNOWLEDGMENTS}

This work was supported by a Career Development Award sponsored by the Association of Teachers of Preventive Medicine 
in collaboration with the Centers for Disease Control and Prevention, Cooperative Agreement U50/CCU300860 (M.T.S.).

\section{References}

1. Slack J, Evans KA. The increased risk of death from ischaemic heart disease in first-degree relatives of 121 men and 96 women with ischaemic heart disease. J Med Genet 1966;3:239-257.

2. Friedlander Y, Kark JD, Stein Y. Family history of myocardial infarction as an independent risk factor for coronary heart disease. Br Heart J 1985;53:382-387.

3. Thomas CB, Cohen BH. The familial occurrence of hypertension and coronary artery disease, with observations concerning obesity and diabetes. Ann Intern Med 1955;42:90-127.

4. Lloyd-Jones DM, Nam B-H, D’Agostino RB Sr, Levy D, et al. Parental cardiovascular disease as a risk factor for cardiovascular disease in middle-aged adults. A prospective study of parents and offspring. JAMA 2004;291:2204-2211.

5. Hunt SC, Williams RR, Barlow GK. A comparison of positive family history definitions for defining risk of future disease. J Chronic Dis 1986;39:809-821.

6. Silberberg JS, Wlodarczyk J, Fryer J, Ray CD, et al. Correction for biases in a population-based study of family history and coronary heart disease. The Newcastle Family History Study I. Am J Epidemiol 1998;147:1123-1132.

7. Ciruzzi M, Schargrodsky H, Rozlosnik J, Pramparo P, et al. Frequency of family history of acute myocardial infarction in patients with acute myocardial infarction. Am J Cardiol 1997;80:122-127.

8. Leander K, Hallqvist J, Reuterwall C, Ahlbom A, et al. Family history of coronary heart disease, a strong risk factor for myocardial infarction interacting with other cardiovascular risk factors: results for the Stockholm Heart Epidemiology Program (SHEEP). Epidemiology 2001;12:215-221.

9. Roncaglioni MC, Santoro L, D'Avanzo B, Negri E, et al. Role of family history in patients with myocardial infarction. An Italian case-control study. GISSI-EFRIM Investigators. Circulation 1992;85:2065-2072.

10. Bertuzzi M, Negri E, Tavani A, LaVecchia C. Family history of ischemic heart disease and risk of acute myocardial infarction. Prev Med 2003;37:183-187.

11. Brown DW, Giles WH, Burke W, Greenlund KJ, et al. Familial aggregation of earlyonset myocardial infarction. Community Genet 2002;5:232-238.

12. Nora JJ, Lortscher RH, Spangler RD, Nora AH, et al. Genetic-epidemiologic study of early-onset ischemic heart disease. Circulation 1980;61:503-508.

13. Sesso HD, Lee I-M, Gaziano M, Rexrode KM, et al. Maternal and paternal history of myocardial infarction and risk of cardiovascular disease in men and women. Circulation 2001;104:393-398.

14. Taylor AJ, Bindeman J, Bhattarai S, Feuerstein IM, et al. Subclinical calcified atherosclerosis in men and its association with a family history of premature coronary heart disease in first- and second-degree relatives. Prev Cardiol 2004;7:163-167.

15. Scheuner MT, Whitworth WC, McGruder H, Yoon PW, et al. Expanding the definition of a positive family history for early-onset coronary heart disease. Genet Med.

16. Kinra S, Davey Smith G, Okasha M, McCarron P, et al. Is maternal transmission of coronary heart disease risk stronger than paternal transmission? Heart 2003;89:834838.

17. Wilson PWF, D’Agostino RB, Levy D, Belanger AM, et al. Prediction of coronary heart disease using risk factor categories. Circulation 1998;97:1837-1847.

18. National Cholesterol Education Program (NCEP) Expert Panel on Detection, Evaluation, and Treatment of High Blood Cholesterol in Adults (Adult Treatment Panel III). Third Report of the National Cholesterol Education Program (NCEP) Expert Panel on Detection, Evaluation, and Treatment of High Blood Cholesterol in Adults (Adult Treatment Panel III) final report. Circulation 2002;106:3143-3421.
19. Sheridan S, Pignone M, Mulrow C. Framingham-based tools to calculate the global risk of coronary heart disease: a systematic review of tools for clinicians. J Gen Intern Med 2003;18:1039-1052.

20. Poulter N. Global risk of cardiovascular disease. Heart 2003;89 Supplement(Suppl 2):ii2-5.

21. Rich EC, Burke W, Heaton CJ, Haga S, et al. Reconsidering the family history in primary care. J Gen Intern Med 2004;19:273-280.

22. Gramling R, Nash J, Siren K, Eaton C, et al. Family physician self-efficacy with screening for inherited cancer risk. Ann Fam Med 2004;2:130-132.

23. Suther S, Goodson P. Barriers to the provision of genetic services by primary care physicians: a systematic review of the literature. Genet Med 2003;5:70-76.

24. Yarnall KS, Pollak KI, Ostbye T, Krause KM, et al. Primary care: is there enough time for prevention? Am J Public Health 2003;93:635-641.

25. American Medical Association. Family history tools. March 25, 2005. http://www.amaassn.org/ama/pub/category/2380.html. Accessed 13 March 2006.

26. American Society of Human Genetics. Your family history. http://www.ama-assn.org/ ama/pub/category/2380.html. Accessed 13 March 2006.

27. National Society of Genetic Counselors. Your family history-your future. http:// www.nsgc.org/consumer/familytree/index.asp. Accessed 13 March 2006.

28. Centers for Disease Control and Prevention. Genomics and disease prevention. http:// www.cdc.gov/genomics/fHix.htm. Accessed 13 March 2006.

29. United States Department of Health and Human Services. U.S. Surgeon General's Family History Initiative. December 16, 2005. http://www.hhs.gov/familyhistory/. Accessed 13 March 2006

30. Pollard WE. Use of consumer panel survey data for public health communication planning; an evaluation of survey results. In: Proceedings of the Section on Health Policy Statistics. Alexandria, VA: American Statistical Association; 2002:2720-2724.

31. Scheuner MT, Wang S-J, Raffel LJ, Larabell SK, et al. Family history: a comprehensive genetic risk assessment method for the chronic conditions of adulthood. Am J Med Genet 1997;71:315-324.

32. Scheuner MT. Genetic evaluation for coronary artery disease. Genet Med 2003;5: 269-285.

33. Tavani A, Augustin L, Bosetti C, Giordano L, et al. Influence of selected lifestyle factors on risk of acute myocardial infarction in subjects with familial predisposition for the disease. Prev Med 2004;38:468-472.

34. Michos ED, Vasamreddy CR, Becker DM, Yanek LR, et al. Women with a low Framingham risk score and a family history of premature coronary heart disease have a high prevalence of subclinical coronary atherosclerosis. Am Heart J 2005; 150: 1276-1281.

35. Yoon PW, Scheuner MT, Gwinn M, Khoury MJ, et al. Awareness of family health history as a risk factor for disease-United States, 2004. MMWR Morb Mortal Wkly Rep 2004;53:1044-1047.

36. Hoff JA, Daviglus ML, Chomka EV, Krainik AJ, et al. Conventional coronary artery disease risk factors and coronary artery calcium detected by electron beam tomography in 30,908 health individuals. Ann Epidemiol 2003;13:163-169.

37. Friedlander Y, Arbogast P, Schwartz SM, Marcovina SM, et al. Family history as a risk factor for early onset myocardial infarction in young women. Atherosclerosis 2001;156:201-207.

38. Bensen JT, Liese AD, Rushing JT, Province M, et al. Accuracy of case reported family history: the NHLBI Family Heart Study (FHS). Genet Epidemiol 1999;17:141-150.

39. Kee F, Tiret L, Robo JY, Nicaud V, et al. Reliability of reported family history of myocardial infarction. BMJ 1993;307:1528-1530.

40. Hastrup JL, Hotchkiss AP, Johnson CA. Accuracy of knowledge of family history of cardiovascular disorders. Health Psychol 1985;4:291-306.

41. Murabito JM, Nam B-H, D'Agostino Lloyd-Jones DM, et al. Accuracy of offspring reports of parental cardiovascular disease history: the Framingham Offspring Study. Ann Intern Med 2004;140:434-440. 